\title{
PENGARUH LOW SELF-ESTEEM TERHADAP KEINTIMAN SUAMI ISTRI: SUATU STUDI KASUS SUAMI ISTRI
}

\author{
Julianto Simanjuntak ${ }^{1)^{*}}$
}

1) Dosen Program Pascasarjana Sekolah Tinggi Theologia Jaffray

${ }^{*}$ Penulis korespondensi: indonesiapelikan@gmail.com

\begin{abstract}
Abstrak
Studi kasus konseling Kristen untuk mengetahui pengaruh Low Self-Esteem terhadap keintiman suami istri pada beberapa kasus. Kesimpulan dari studi kasus ini adalah: Pertama, masalah suami-istri ini tidaklah sederhana. Apalagi krisis ini telah berlangsung selama lebih 8 tahun. Namun bagaimanapun keluarga Kristen selalu memiliki hope di dalam Kristus. Salah satu tugas penting bagi BS dan pasangannya adalah membangun self-esteem, dari low selfesteem ke self-esteem yang lebih sehat (healthy self-esteem). Kedua, BS dan istrinya perlu belajar untuk lebih terbuka satu dengan lainnya. Selama pengalaman konseling dengan keluarga ini, saya memperhatikan hanya istrinya yang terbuka. BS sangat tertutup, dan segan mengungkapkan isi hatinya. Dalam hal ini BS memang masih memerlukan bantuan, terutama dari pasangannya, untuk lebih dapat terbuka. Ketiga, alangkah baiknya jika mereka terus mengikuti bimbingan dalam marriage enrichment. Gereja seharusnya menciptakan atau mengkondisikan gereja sebagai the healing community; salah satu wujudnya adalah dengan menciptakan kelompok kecil yang teraupetik bagi keluarga-keluarga yang ada dalam jemaat tersebut.
\end{abstract}

Kata kunci: Low Self-Esteem, suami istri, konselor, konseling, gereja, Kristen, kelompok

A Christian counseling case study in order to know the influence of Low Self-Esteem in the intimacy of a husband and wife as revealed in several cases. The summary of this case study is: First, the problem between the husband and wife is not simple. What's more the crisis has been happening for more than 8 years. However, the Christian family, nevertheless, always has hope in Christ. One of the important things for BS and his partner is to build self-esteem, from low self-esteem, to a healthier self esteem. Second, BS and his wife need to learn to be more open with one another. As long as I have counseled with this family, I have noticed that only the wife is open. BS is very closed and reluctant to express what is in his heart. In this matter, BS still needs help, especically from his partner, to be more open. Third, how good it would be if they continued mentoring in marriage enrichment. The church should create or condition the church to be a healing community; one form of this would be with the creation of small therapy groups for families that are in the congregation.

Key words: Low Self-Esteem, husband and wife, counselor, counseling, church, Christian, group 


\section{Pendahuluan}

Studi kasus suami istri ini bertujuan untuk mengetahui pengaruh Low Self-esteem terhadap keintiman suami istri. Melalui suatu studi kasus yang didukung oleh teori tentang Self-esteem dan faktor-faktor Low Selfesteem dan faktor-faktor keintiman dalam pernikahan dapat menjawab studi kasus BS melalui pendekatan konseling Kristen.

\section{Studi Kasus}

BS, seorang pria berusia 33 tahun. Ia mengalami cukup banyak konflik dalam pernikahannya. Ia sulit membangun intimacy, dalam segala bentuknya, dengan sang istri. Hal ini sangat berhubungan dengan pengalaman masa lalunya. Sejak kanak-kanak ia mengalami situasi yang membuatnya miskin secara emosi.

Pertama, ayahnya menikah lagi saat BS berusia masih 3 tahun. Hal ini membuat perhatian ayahnya terbagi-bagi. Dari istri pertama saja, ayahnya mempunyai 7 anak. Di samping itu ia sering melihat ayah dan ibu kandungnya bertengkar sengit dan disertai dengan pemukulan yang kasar terhadap ibunya.

Kedua, BS pernah dititipkan pada keluarga Om-nya, namun karena BS tidak senang dan sering menangis, ia dikembalikan kepada orang tua kandungnya. Pengalaman ini menimbulkan perasaan tertolak.

Ketiga, ayahnya meninggal dunia saat ia masih berusia 6 tahun. Saat itu ia masih sangat membutuhkan figur ayah.

Keempat, kepergian ayahnya membuat ekonomi rumah tangga mereka makin morat marit serba berkekurangan. Hal ini membuat BS harus kehilangan masa kecilnya karena harus membantu ibu kandungnya di warung. Akibatnya, ia tidak mempunyai teman. Bahkan teman-temannya menolak dan mencela BS sebagai anak 'banci'.

Kelima, perasaan tertolak, tidak berharga atau minder diperparah karena BS sering terlambat membayar uang sekolah. Jadi, ia tidak hanya diejek di sekitar rumahnya, tapi juga oleh teman-teman sekolahnya. Semua pengalaman ini akhirnya membentuk low self esteem dalam diri BS.

Secara akademik ia hanya lulus SLTA dan tidak memiliki ketrampilan yang memadai untuk bekerja. Di pihak lain perasaan ingin memiliki teman dekat sangat kuat di dalam dirinya. Itu sebabnya ketika masih berusia 23 tahun, dan berkenalan dengan seorang janda berusia 30 tahun (jadi lebih tua 7 tahun), BS mendesak wanita itu untuk segera menikah. Sang Janda itu sendiri mau menikah dengan BS karena menginginkan seorang pelindung bagi dirinya dan tiga anaknya. Karena dua motivasi dan kebutuhan yang bertolak belakang itu tidak heran selama lebih 8 tahun menikah BS sulit membangun keintiman dengan istrinya; sebaliknya, terus-menerus konflik. 


\section{Faktor-Faktor Low Self-esteem}

\section{Pengertian Self-esteem}

Menurut New Dictionary of Christian Ethics and Pastoral Theology', Self esteem merupakan satu bagian yang esensial dari keberadaan kita sebagai manusia. Ini merupakan inti yang terdalam dari kepribadian. Dari self ini individu dapat mengenali dan mengemukakan siapa dirinya, terlepas dari pandangan orang lain.

Collins membedakan antara self-esteem dengan self-concept dan selfimage. Ia berpendapat self-concept dan self-image lebih menunjuk kepada suatu deskripsi diri (a self-description), sedangkan self-esteem menunjuk kepada suatu evaluasi diri (a self evaluation). ${ }^{2}$

Dalam bukunya Counseling and Self-esteem, David Carlson menjelaskan bahwa self-esteem memiliki enam dimensi, yakni: ${ }^{3}$
a. Feelings
: what do I feel toward me? (emotions)
b. Beliefs
: what do I believe about me? (convictions)
c. Values
: How much do I value me? (worth)
d. Perceptions
: How do I see myself? (images)
e. Conversations
: How do I sound to myself? (self-talk)
f. Actions
: How do I act? (behaviors)

Self-esteem ada tiga level yakni, healthy self-esteem, pride dan low selfesteem. Mereka yang healthy, melihat dirinya secara realistik. Sedang yang pride dan low self-esteem tidak realistik. Yang pride, cenderung merasa diri superior terhadap orang lain, sebaliknya yang low merasa dirinya lebih rendah (inferior) daripada orang lain.

Menurut Carlson orang yang healthy self-esteem ditandai dengan beberapa ciri: ${ }^{4}$

a. Humility (rendah hati), tetapi bukan humiliation (perasaan malu dan rendah diri).

b. Putting of the sinful nature (mematikan keinginan dosa). Namun ini tidak sama dengan putting down self.

c. Self-denial (menyangkal diri). Namun ini tidak sama dengan menghina diri (self degradation).

d. merasa tidak patut/layak (unworthy), namun bukan worthless atau merasa diri tidak berharga.

\footnotetext{
${ }^{1}$ David Atkinson (Ed.), New Dictionary of Christian Ehics and Pastoral Theology (England: Inter-Varsity Press, 1995), 773-774.

${ }^{2}$ Gary Collins, Christian Counseling (Texas: Word Books, 1980), 347.

${ }^{3}$ David E. Carlson, Counseling and Self-esteem (Dallas: Word Publishing, 1988), 25.

${ }^{4}$ David E. Carlson, Counseling and Self-esteem, 29.
} 
e. Self-love, atau mengasihi diri sendiri. Ini tidak sama dengan selfishness (egois).

f. Self worth (menghargai diri), namun bukan self-worship (memuja diri).

g. Self aware (menyadari diri), namun bukan self absorbed (terlalu memikirkan diri).

Sebaliknya individu dengan low self-esteem biasanya mempunyai kecemasan yang besar dan rasa ketidakpastian tentang dirinya sendiri. Mereka cenderung negatif terhadap perkataan, gambaran diri, perasaan diri, dan tingkah laku diri mereka sendiri. Menurut Virginia Satir ${ }^{5}$ individu dengan low self-esteem cenderung menggantungkan harga dirinya pada penilaian orang lain terhadap dirinya. Ia sangat haus pada penghargaan orang lain, oleh karena itu ia cendrung mau menyenangkan orang lain pula.

Faktor-faktor Low Self-esteem

Self-esteem sendiri secara umum (general) terdiri dari tiga hal: academic self-esteem, social self-esteem, dan physical self-esteem.

Academic self-esteem. Self-esteem individu sangat dipengaruhi oleh kemampuan akademik individu. Secara akademik, ada individu yang menonjol, kurang menonjol atau sama sekali tidak menonjol (di bidangbidang tertentu). Dilihat dari kemampuan akademik maka BS, dengan kondisi tinggal di kota besar seperti Jakarta, boleh disebut kurang menonjol. Ia tidak memiliki kelebihan tertentu di bidang akademis. Di samping itu ia hanya lulus SMEA dengan nilai biasa saja. Ia memang punya keinginan meneruskan sekolah sampai ke perguruan tinggi. Namun kondisi ekonomi keluarga tidak mendukung hal itu. Menurut pengakuannya, ini membuatnya sering menyesal dan kecewa dan kecil hati.

Social self-esteem. Sumber perasaan harga diri sosial ini umumnya yang berasal dari orang tua dan teman sebaya (peers). Dari orang tua, BS sangat sedikit mendapatkan penerimaan (acceptance) di tengah keluarga. Ia dibesarkan dalam keluarga yang dysfunction. Ketika ia masih berumur 3 tahun sang ayah menikah lagi, sehingga harus membagi perhatiannya dengan istri kedua. Sang ibu kandungnya sendiri tidak punya waktu yang cukup untuk mengurus ke tujuh anaknya karena harus mencari nafkah setelah ayahnya meninggal dunia waktu BS berusia 6 tahun. Menurut Atkinson, self esteem bertumbuh secara bertahap melalui hubungan yang hangat dengan orang tua. ${ }^{6} \mathrm{Hal}$ ini sesuai dengan apa

\footnotetext{
${ }^{5}$ Virginia Satir, Conjoint Family Therapy (California: Science and Behavior Books, Inc., 1983), 9.

${ }^{6}$ Atkinson, 774 .
} 
yang disaksikan oleh Yohanes, ${ }^{7}$ bahwa "orang yang belum mengalami kasih sulit mengasihi dengan sungguh-sungguh." Dari teman sebaya, BS lebih banyak mendapatkan banyak penolakan dari teman sebayanya. Ia sering dicemooh, misalnya dengan julukan banci. Hal ini menimbulkan penderitaan yang hebat. Sebab menurut Hurlock, pada masa remaja umumnya mereka menghendaki popularitas dan kasih sayang dari teman sebaya, terutama jika mereka merasa tidak mendapat kasih sayang di rumah. Demi membantu ibunya berjualan, ia kehilangan sebagai besar masa kanak-kanak dan remajanya. ${ }^{8}$

Physical Self-esteem. Penerimaan diri secara fisik ditentukan oleh dua hal, yakni appearance dan physical skill. Pertama, Appearance: BS sendiri berpenampilan kecil, kurus dan pendek. Sepintas memang kurang menarik. Dalam penelitian Jourard dan Secord memperlihatkan bahwa laki-laki mempunyai kepuasan dengan tubuh mereka bila mereka bertubuh besar. Di kalangan remaja ukuran tubuh yang lebih besar menawarkan kesempatan ke arah prestise dan kekuasaan bagi pria. ${ }^{9}$ Dalam serangkaian studi lainnya Jourard dan Secord menemukan bahwa perasaan-perasaan yang dimiliki seorang individu tentang tubuh fisiknya berkorelasi dengan perasaannya tentang dirinya secara umum. ${ }^{10}$ Dengan perkataan lain perasaan harga diri berkorelasi dengan sikap penerimaan dari tubuh fisik seseorang. Kedua, physical skill, BS juga tidak mempunyai skill atau physical ability yang cukup. Karena itu ia sulit mendapatkan pekerjaan. Sebaliknya sang istri adalah seorang yang sangat mahir menjahit. Justru dari hasil jahitan sang istri inilah keluarga ini bisa survive, bahkan memiliki rumah yang permanen. Dalam keadaan dan situasi itu BS terpaksa menjalankan role layaknya seorang istri. Ia memasak, mencuci dan membersihkan rumah, sebab istrinya harus konsentrasi pada proyek jahitan. Perasaan BS sangat menderita. Namun ia tidak punya daya keluar dari jerat tersebut.

Self-esteem dan Self-love. Keith Plummer dalam tulisannya Selfisness and Self-Esteem, mengindentikkan 'self-esteem' dan 'self-love'. Menurut Plummer, tanpa memiliki self-esteem yang cukup seseorang tidak mungkin dapat mencintai sesamanya dengan benar. Sebab ia akan terus-menerus

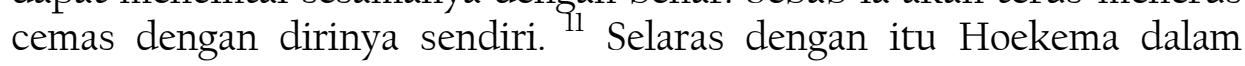
bukunya, Created in God's Image berkata:

\footnotetext{
${ }^{7} 1$ Yohanes 4:19 (TB).

${ }^{8}$ Elizabeth B. Hurlock, Perkembangan Anak Jilid I (Jakarta: Erlangga, 1991), 253.

${ }^{9}$ R. B. Burns, Konsep Diri ( Jakarta: Arcan, 1993), 191.

${ }^{10}$ Burns, 196.

${ }^{11}$ Keith Plummer, Selfishness and Self-Esteem Moody Magazine, March/April 1997, 21.
} 
... a person who has an extremely negative self-image, who thinks of himself as totally worthless, will not be able effectively to love his neighbor as himself; he will not give himself to his neighbor in fellowship, since he feels he has nothing worthwhile to give. On the other hand, a person with positive self-image... will be willing to give herself to another in fellowship, and thus fulfill the command to love the neighbour. ${ }^{12}$

Self-esteem tidak dapat dipisahkan dengan kehidupan atau pemahaman religius individu. Atau dengan istilah lain, Eric L. Johnson, mengatakan pemahaman self-esteem berakar pada pemahaman religius individu. Dalam salah satu tulisannya ia berkata "Consequently, one's experience of self-esteem is inherently rooted in religious issues (explicitly for the Christian and inplicitly for the secularist). Who or what our gods are shapes our selfesteem. $^{13}$

Sesudah jatuh dalam dosa self-image manusia tercemar. Pada awalnya Allah menciptakan manusia sebagai the Image of God. Allah sendiri yang memberikan label itu pada manusia. ${ }^{14}$ Menurut Richard Pratt, manusia sebenarnya memiliki dua hal secara seimbang, yakni Humility Image of God" dan "Dignity Image of God. ${ }^{15}$ Namun setelah Adam dan Hawa jatuh dalam dosa, Allah menanyakan Adam mengenai identitasnya, Adam menyembunyikan diri. Ia tidak sanggup memberi identitasnya ketika Tuhan bertanya, "Hai Adam, di manakah engkau?"16

Menurut Hoekema sesudah kejatuhan self-image manusia menjadi rusak atau tidak wajar. Ketidakwajaran itu menjadi dua ekstrem. Pertama, self-image manusia terlalu dilebihkan atau ditinggikan oleh manusia itu sendiri. Hal ini kita lihat dalam bentuk kesombongan (sinful pride). Manusia cenderung melihat dirinya lebih daripada yang sesungguhnya. Manusia cenderung menjadi otonomi, dan menjauh dari Allah (independent). ${ }^{17}$

Kedua, manusia memiliki low self-image. Manusia cenderung menilai dirinya lebih rendah dari apa yang sebenarnya. Ia tidak dapat melihat dirinya sebagai 'the Image's of God'. Bahkan manusia cenderung menghina dirinya dan membenci dirinya. Sebagai orang percaya, maka tiap kita

${ }^{12}$ Anthony, Hoekema, Created in God's Image (Grand Rapids, Michigan: Wm. B. Eerdmans Publishing Co., 1986), 102.

${ }^{13}$ Eric L. Johnson, "Self-Esteem in the Presence of God," Journal of Psychology and Theology 17, No. 3 (1989):227.

${ }^{14}$ Genesis 1:26 "Let Us make man in our image, in Our likeness..."

${ }^{15}$ Richard Pratt Jr., Designed For Dignity (New Jersey: P \& R Publishing, 1993), 4.

${ }^{16}$ Kejadian 3:7-10.

${ }^{17}$ Hoekema, 104-105. 
dipanggil untuk menjadi semakin dewasa menuju gambar khalik-Nya. Salah satu dari tugas itu adalah memiliki self-esteem yang sesuai dengan Kitab Suci. Sebab tanpa memiliki tanpa self-esteem yang cukup maka sulit bagi kita menuruti perintah Tuhan agar kita saling mengasihi.

\section{Faktor-faktor Intimacy Dalam Pernikahan}

\section{Pengertian Intimacy}

Intimacy merupakan komponen emosional dari cinta. Menurut Stenberg, intimacy menghadirkan kepada perasaan-perasaan 'closeness, connectedness, and boundedness' dalam hubungan yang saling mencintai. ${ }^{18} \mathrm{Di}$ dalamnya termasuk perasaan-perasaan yang menimbulkan kehangatan dengan orang yang dicintai.

Menurut Norman Wright, Direktur Christian Marriage Enrichment di Amerika, intimacy adalah:

Jalinan kasih sayang, tali pengikat yang terbentuk oleh perhatian, tanggung jawab, kepercayaan, komunikasi perasaan dan sensasi secara terbuka, yang bersifat timbal balik, demikian pula saling menukar informasi mengenai peristiwa-peristiwa emosional penting, tanpa saling menyakiti. ${ }^{19}$

Pengalaman intimacy ini dapat membuat seseorang menghargai pasangannya dan ingin membuatnya bahagia. Keintiman adalah sikap saling mengerti akan kebutuhan orang yang dicintainya, terbuka, saling menerima dan memberi dukungan secara emosional satu dengan yang lain.

Intimacy merupakan komponen cinta yang penting dan menunjang dua komponen lainnya, yakni passion dan commitment. Ketiganya membentuk cinta yang kokoh dan utuh. Intimacy merupakan kebutuhan mendasar dari setiap manusia. Sebab umumnya setiap orang ingin merasa dekat, saling mencintai, saling memperhatikan dan diperhatikan. Jika seseorang kurang mendapatkan keintiman ini sejak masa kecilnya, maka kemungkinan besar sulit pula menerapkannya ketika memasuki pernikahan. Intimacy ini meliputi antara lain: emotional intimacy (keintiman emosional), social intimacy (keintiman sosial), intelectual intimacy (keintiman intelektual, recreational intimacy, dan sexual intimacy (keintiman seksual).

${ }^{18}$ Robert, Stenberg. “A Tringular Theory of Love," Psychological Review 93, No. 2 (1986):119.

${ }_{19}$ Norman Wright, Pertanyaan-pertanyaan Pribadi Yang Sering Diajukan Para Wanita (Solo: Dabara Publisher, 1993), 106. 


\section{Pengaruh Low SelfEsteem Terhadap Keintiman Pernikahan}

Low Self-esteem sangat mempengaruhi keintiman pernikahan. Dari hasil-hasil penelitian yang dicatat Glenn Wilder, ternyata self-esteem menjadi salah satu dasar kebahagiaan dan penyesuaian diri yang sehat dari individu. Jikalau individu memiliki low self-esteem maka ia akan mengalami banyak kesukaran dalam penyesuaian diri. ${ }^{20}$ Dari deskripsi analisa di atas maka saya menjumpai ada lima pengaruh low self-esteem dalam pernikahan BS.

Pertama, BS sulit mengungkapkan emosinya kepada pasangannya Hal ini sangat dipengaruhi oleh latar belakang BS. Kegagalan orangtua BS di masa lalu telah membentuk perasaan yang insecure di dalam dirinya. Seperti yang ditulis oleh Janice dan Kimberly, bahwa konteks sosial serta latar belakang historis seseorang turut membentuk cara mengungkapkan dan menerima sistem-sistem emosi individu. ${ }^{21}$ Jika individu mendapatkan banyak reaksi emosi negatif pada masa kanakkanak, maka setelah dewasa reaksi yang negatif itu juga yang lebih berkembang.

Senada dengan itu Hillary R. Clinton berpendapat bahwa, anakanak dari keluarga orangtua tunggal mempunyai peluang mengalami masalah emosi atau perilaku dua atau tiga kali lebih besar dibanding mereka yang tinggal bersama orang tua ganda. ${ }^{22}$ Dari kasus di atas kita mengerti bahwa BS sejak kanak-kanak pernah merasa terbuang, oleh karena pernah dititipkan kepada orang lain. Ia mengalami trauma melihat konflik yang tajam antara ayah dan ibunya; sang ayah menikah lagi, sampai pada akhirnya sang ayah meninggal dunia saat BS masih 6 tahun.

Kedua, ketidakmampuan BS mengungkapkan maupun menerima emosi dari sang istri mengembangkan semacam perasaan guilt, fear baik kepada istri maupun dirinya sendiri. Tidak mengherankan jika BS sering takut atas sikap otoriter sang istri dan membuatnya semakin ragu memainkan role sebagai suami. BS sulit memahami reaksi-reaksi emosi yang sedang terjadi di dalam dirinya maupun istrinya karena ia sendiri terlalu banyak menuntut dari pasangannya. Menurut Daniel Goleman, justru faktor ini yang sering menghambat proses keintiman dalam

${ }^{20}$ Glenn, Wilder, "The Search For Self-esteem," Journal Psychology and Theology 6, No. 1 (1978):183.

${ }^{21}$ Janize Zeman and Kimberly Shipman, "Children's Expression of Negative Affect: Reasons and Methods," Development Psychology 32, No. 5 (1996):842.

${ }^{22}$ Hillary R. Clinton, Menyiapkan Masa Depan Yang Cerah Bagi Anak (Jakarta: Gramedia, 1995), 31. 
banyak pasangan keluarga, bahkan menimbulkan banyak perceraian di seluruh dunia. 23

Ketiga, hal-hal di atas juga berkaitan dengan motif BS menikah. Ia menikah hanya karena merasa membutuhkan seorang teman yang bisa mengobati kesepian dan kekecewaan dirinya. Mencari istri yang dapat menerima dan memperhatikannya. Namun sayang, justru ia menikahi seorang janda yang juga sedang mengalami kepahitan hidup karena perceraiannya.

Perceraian memang suatu pengalaman yang sangat menyakitkan. Gary Collins mengatakan:

Divorce is painful-very painful. It can thoroughly disrupt one's life, routines, feelings of self-worth, and sense of security. It can affect people physically, psychologically, and spiritually. It can lead emotionnal up-heaval, irrational decisions and interpersonal tensions. ${ }^{24}$

Tidak heran dalam kondisi yang painful itu sang janda berharap dalam pernikahan kedua nanti ia mendapat suami yang dapat melindungi dan mengasihinya. Dengan perkataan lain ia menikah dengan seorang wanita yang juga memiliki low self-esteem. (Istri BS juga sempat menceritakan bahwa ia memiliki perasaan tidak aman, bahkan depresi berat karena statusnya itu).

Keempat, BS inferior terhadap istrinya karena perbedaan umur yang menyolok sekali. BS lebih muda 7 tahun dari sang istri. Secara emosional istri nya juga jauh lebih matang dari BS. Di samping itu juga memiliki keahlian yang sangat baik di dalam menjahit. Dari keahlian menjahit ini mereka hidup secara memadai sampai hari ini. Sebaliknya BS tidak memiliki keahlian apapun. Sebagai seorang pria dan suami hal tersebut membuatnya menjadi ragu dalam memainkan role sebagai suami di rumah. Ia merasa tidak pantas untuk memimpin istrinya.

Jikalau kita memperhatikan teori Erikson, Ini sangat dipengaruhi oleh karena BS tidak melewati masa krisis tahap tiga, yakni initiative vs guilt. Sebab pada usia sekitar 4-5 tahun anak berusaha mengenali dirinya dengan mengimitasi ayahnya. Namun justru saat usia itu terjadi krisis dalam kehidupan ayah dan ibunya. ${ }^{25}$ BS ragu memainkan role sebagai suami. Bahkan ironisnya, ia malah memainkan role sebagai istri. Ia memasak, mencuci, dan mengurus anak setiap hari, sebab sang istri harus lebih konsentrasi pada tugas menjahit.

\footnotetext{
${ }^{23}$ Daniel Goleman, Kecerdasan Emosional (Jakarta: Gramedia, 1995), 182.

${ }^{24}$ Collins, 191.

${ }^{25}$ Guy Lefrancois. OfChildren (California: Wadsworth Publishing Co., 1973), 48.
} 
BS takut mengemukakan perasaan-perasaan yang tidak enak ini terhadap istrinya, sebab ia takut terluka. Ia takut ditolak dan dilecehkan oleh istrinya. Menurut Rollo May dalam bukunya The Meaning of Anxiety, low self-esteem sangat berkorelasi dengan kecemasan. ${ }^{26}$ Orang orang yang dengan low self-esteem mudah sekali cemas. Itu sebabnya jika istrinya marah, BS lebih memilih diam dari pada menanggung resiko yang lebih besar, yakni ditolak oleh istri. Bahkan ketika ia tidak tahan lagi menghadapi konflik dengan istrinya, BS secara diam-diam pulang ke rumah ibu kandungnya. Hal ini justru makin menambah kejengkelan dan kemarahan sang istri.

\section{Kesimpulan}

Pertama, masalah suami-istri ini tidaklah sederhana. Apalagi krisis ini telah berlangsung selama lebih 8 tahun. Namun bagaimanapun keluarga Kristen selalu memiliki hope di dalam Kristus. Salah satu tugas penting bagi BS dan pasangannya adalah membangun self-esteem, dari low self-esteem ke self-esteem yang lebih sehat (healthy self-esteem). Untuk itu konselor perlu membantu mereka.

Kedua, BS dan istrinya perlu belajar untuk lebih terbuka satu dengan lainnya. Selama pengalaman konseling dengan keluarga ini, saya memperhatikan hanya istrinya yang terbuka. BS sangat tertutup, dan segan mengungkapkan isi hatinya. Demikian juga dari pengakuan sang istri. Dalam hal ini BS memang masih memerlukan bantuan, terutama dari pasangannya, untuk lebih dapat terbuka. Hal ini dibutuhkan agar masing-masing lebih realistis terhadap pasangannya. Disamping itu mereka perlu belajar saling membangun self-esteem pasangannya. ${ }^{27}$

Ketiga, alangkah baiknya jika mereka terus mengikuti bimbingan dalam marriage enrichment. Sebab kelompok itu dapat menjadi kelompok yang terapeutik (group therapy) bagi pemulihan hubungan mereka yang telah lama saling terluka. Untuk itu gereja perlu memberi perhatian dan bimbingan yang serius terhadap pergumulan jemaatnya agar memiliki kehidupan pernikahan yang sehat. Gereja seharusnya menciptakan atau mengkondisikan gereja sebagai the healing community; salah satu wujudnya

${ }^{26}$ Rollo May, The Meaning of Anxiety (New York: WW Norton \& Company Inc., 1996.), 114-115.

${ }_{27}$ Rainey mengusulkan beberapa sikap untuk saling membangun self-esteem pasangannya. a) Accepting unconditionally; b) Putting the past in perspective; c ) planting positive words; d) constructing in difficult times; e) Giving the freedom to fail; f) Pleasing your mate; g) Doing what is right; h) Helping your mate develop friends; i) Dicovering Dignity through destiny. Lihat Dennis dan Barbara Rainey, Moments Together For Couples: Devotions for Drawing Near to God and One Another (Ventura, California: Gospel Light, 1995). 
adalah dengan menciptakan kelompok kecil yang teraupetik bagi keluarga-keluarga yang ada dalam jemaat tersebut.

\section{Kepustakaan}

Atkinson, D. Ed. New Dictionary of Christian Ehics and Pastoral Theology England: Inter-Varsity Press, 1995.

Burns, R. B. Konsep Diri. Jakarta: Arcan, 1993.

Carlson, David. Counseling and Self-Esteem. Dallas: Word Publishing, 1988.

Clinton, Hillary. Menyiapkan Masa Depan Yang Cerah Bagi Anak. Jakarta: Gramedia, 1995.

Collins, Gary. Christian Counseling. Texas: Word Books Publisher, 1980.

Dennis dan Barbara Rainey. Moments Together For Couples: Devotions for Drawing Near to God and One Another. Ventura, California: Gospel Light, 1995.

Goleman, Daniel. Kecerdasan Emosional. Jakarta: Gramedia, 1995.

Hoekema, Anthony . Created in God's Image. Grand Rapids, Michigan: Wm. B. Eerdmans Publishing Co. , 1986.

Hurlock, Elizabeth B. Perkembangan Anak. Jilidl Terj. Meitasari. Jakarta: Penerbit Erlangga, 1991.

Johnson, Eric L. "Self-Esteem in the Present of God." Journal of Psychology and Theology 17, No.3 (1989): 226-235.

Koteskey, Ronald. "Toward The Development of A Christian Psychology: Emotion". Journal of Psychology and Theology 8/4 (Winter 1980):303313.

Lefrancois, Guy R. Of Children: An Introduction to Child and Adolescent Development. California: Wadsworth Publishing Company, 1973.

May, Rollo. The Meaning of Anxiety. New York: WW Norton \& Company Inc., 1996.

Plummer, Keith. "Selfishness and Self-Esteem." Moody, March/ April, 1997.

Pratt, Richard. Designed For Dignity. New Jersey: P \& R Publishing, 1993.

Rainey, Dennis and Barbara. Building Your Mate's Self-Esteem. USA: Here's Life Publisher, 1991.

Satir, Virginia. Conjoint Family Therapy. California: Science and Behavior Books, Inc., 1983.

Stenberg, Robert. "A Tringular Theory of Love." Psychological Review 93, No.2, (1986):119-135.

Wilder, Glenn, "The Search For Self-esteem." Journal Psychology and Theology 6, No.l (Summer 1978): 183-188. 
William, G. Britt. "God's Holiness and Humanity's Self-Esteem.” Journal of Psychology and Theology 16, No. 3 (Falll 1988):213-221.

Wright, Wright. Pertanyaan-pertanyaan Pribadi yang Sering Diajukan Para Wanita. Solo: Dabara Publisher, 1993.

Zeman, Janice and Kimberly Shipman. "Children's Expression of Negative Affect: Reasons and Methods". Development Psychology 32, No. 5 (September 1996):842-849. 